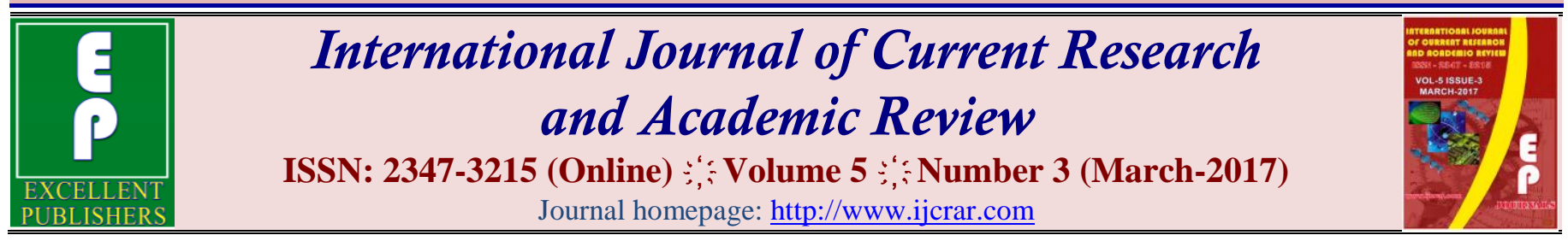

doi: https://doi.org/10.20546/ijcrar.2017.503.003

\title{
Impact of School and Family Background on Mental Health of Adolescents
}

\author{
Preeti Tamta* and Pooja Arya
}

Kumaun University, S.S.J. Campus Almora, Uttarakhand, India

*Corresponding author

\section{Abstract}

The present study intended to analyze the influence of type of school, gender and home environment on mental health. A $2 \times 2 \times 2$ factorial design with two group of school (Private and Government) $\mathrm{x}$ gender $\mathrm{x}$ level of home environment (good and poor) was used in present study. A total 120 adolescents (13-17 yrs) were randomly selected from urban area of Almora city. The home environment inventory was applied to identify the level and form of home environment in adolescents. Mental health inventory were exercised to assess the mental health of adolescents. Results revealed the significant effect of gender and home environment on mental health. Similarly, type of school $\mathrm{x}$ gender interaction effect was found significant.
\end{abstract}

\section{Article Info}

Accepted: 28 February 2017

Available Online: 20 March 2017

\section{Keywords}

Adolescents, Home environment, Mental health.

\section{Introduction}

During the last decades, issues related to health have received major attention in the public and health professionals understanding. Everyone accepts the importance of health and well-being in his /her life. Health is a widely studied area in social-psychological researches. Recent conceptualization of health is made in more positive terms. This view is reflected in the definition of World Health Organization (WHO, 2001) which defines "Health is a state of complete physical, mental and social well-being and not merely the absence of disease or infirmity." Thus health consist three dimension physical, mental, and social well-being.

Mental health is an important aspect of one's total health status and it's a basic factor that contributes to the maintenance of physical health and social effectiveness. It means the ability to balance feelings, desire, ambitions and ideals is one's daily life. It is the ability to face and accepts the realities of life. Mental health has two aspects -individual and social. Social forces are in constant flux. They are constantly moving and changing and therefore our mental health is affected by various stresses. Mental health is a process of adjustment, which involves compromise and adaptation, growth and continuity. Because of significance of individual and social aspects mental health is defined as ability of the individual to make personal and social adjustments. Mental health is the capacity of an individual to form harmonious adjustments to one's social to physical environment.

The field of mental health has made significant progress during the last decades, which is reflected in the large range of ability. Researchers have shown their concern to investigate mental health in relation to numerous factors. A number of personal and contextual factors exercising role in the process of mental health (Kendall-Tackett, 2001), school environments can affect the mental health of students through the academic and social stresses experienced by students. The support of peers and teachers at school can have important consequences for 
student wellbeing. Adolescents who feel that there are people who care about them at school and feel connected to the school are more likely to be academically motivated and less likely to engage in a variety of negative behaviours including drug use, violence and sexual activity (Wentzel, 1997).

A sizeable number of studies indicate that several factors that impact on student mental health since poor mental health has been recognized as suicidal behaviour and lower academic achievement (Kay, Li Xiao Nakkaew and Park, 2009; Puskar and Bernardo, 2007). Several studies have shown that the role of demographical variable such as age and gender, personality trait in mental health (Goodwin and Friedman, 2006; Yen and Cheng, 2006).

Although, studies mentioned earlier indicate demographical characteristics impact on mental health. However, some domains like, contextual factors most important factor that influences the individual's growth. Family is the one of the main element of each society. The foundation of development of individual lies in the womb of the family. The growth of child's personality depends upon the family atmosphere. Through family, he learns the norms of society, interrelationships and become a competent and useful member of society. Parents are supposed to create a most congenial, happy, democratic, lucid and warm atmosphere through their parenting style and through this child develops his hidden potentialities and social interaction skill (Bharadwaj, 1995). A sizeable number of studies indicate that family context abusive treatment by parents pervasive impact on emotional psychological and mental well being (Lanktree et al., 2008; Lazenbatt, 2010). This study seeks to enhance the understanding of mental health in adolescents by selecting an important factors i.e. school setting, and home environment which may assist the positive source of mental health.

\section{Objectives and hypotheses}

Present study was planned to investigate the impact of school setting, gender and home environment on mental health. Following hypotheses were made;

1. The type of school would play positive impact on mental health. More specifically, Government school adolescents would better mental health status than private school adolescents.
2. The levels of mental health also vary in boys and girls. In our society boys are given more freedom and opportunity to experiences than girls.

3. Home environment would also exercise favourable impact on mental health. Therefore, good home environment adolescents would perform better on mental health as compared to poor home environment.

\section{Materials and Methods}

\section{Design}

Present study is based on $2 \times 2 \times 2$ factorial design with two group of school (private and government school) $\mathrm{x}$ Gender (Boys and Girls) x level of home environment (good and poor).

\section{Participants}

A total of 120 adolescent age ranged 13-17 yrs. grade 9 to $12^{\text {th }}$ standards, enrolled in different school of Almora city participated in present study. Stratified random sampling technique was used for sample selection. On the basis of median score obtained on home environment inventory $(\mathrm{mdn}=208)$, adolescents were divided into good and poor home environment groups.

\section{Measures}

\section{Mental health inventory}

This inventory developed by Jagdish and Srivastava (1996) was used to measure mental health. The inventory consisted of 56 items including 32 'false kyed' (negative) and 24 true (positive) statements. The reliability of the inventory was determined by spilt - half method using odd-even procedure. The reliability coefficient of overall inventory was.73 and construct validity of the inventory was 0.54 .

\section{Home Environment Inventory (HEI)}

The home environment inventory (1989) constructed by Mishra Karuna Shankar. HEI has 100 items related to ten dimension of home environment. The HEI has five point scale. Response of each item were scored following 4, $3,2,1,0$. The scored could range from 0 to 400. Its re-test reliability was also found to be high ( $r=0.73$ to 0.95 ). 


\section{Procedure}

The present study was conducted in two phases. In the Ist phase adolescents were contacted in school setting and requested to cooperated. After getting their consent they were briefed about the nature and aims of the study. After receiving the initial willingness their background information were collected on the basis of Personal Data Sheet (PDS). Then Home environment Inventory (HEI) was administered one by one and they were requested to response carefully. Adolescents were assured that their response would be kept confidential. This HEI was used to identify the cases of good and poor home environment of adolescents. Afterward In the $2^{\text {nd }}$ phase of the study, the participants were given mental health inventory. After completing their responses they were thanked for cooperation and data were collected and scored according defined rules.

\section{Results and Discussion}

To determine the impact of type of school, gender and home - environment on various dimensions of mental health, a $2 \times 2 \times 2$ factorial analysis of variance was computed. Obtained results are displayed in table and figures reported below.

As table 1 displays the significant main effect of gender $[\mathrm{F}(1,112)=33.440, \quad \mathrm{P}<.01]$ which denote that girls $(\mathrm{M}=153.52)$ were found inferior on mental health as compared to boys $(M=163.21)$. Main effect of home environment was found to be significant $[\mathrm{F}(1,112) 96.356, \mathrm{P}<.1]$ which denote that poor home environment $(M=150.15)$ adolescents unhealthy mental health as compared to good home environment adolescents $(\mathrm{M}=166.59)$.

Type of school $x$ gender Interaction effect (Fig. 1) was found to be significant $[\mathrm{F}(1,112)=.20 .457, \mathrm{P}<.01]$ Interaction graph show that in government group boys adolescents performed superior on mental health as compared to girls. Similarly a consistent pattern of increment was observed in case of private group adolescents. Findings of the present study evinced the adverse consequences of poor home environment on mental health. Poor home environment group was found inferior on mental health as compared to good homeenvironment group.

Table.1 Mean and S.D.s of mental health as function of type of school gender and home environment

\begin{tabular}{|l|l|l|l|l|l|l|l|l|}
\hline \multicolumn{4}{|c|}{ Private } & \multicolumn{3}{c|}{ Government } \\
\hline \multicolumn{3}{|c|}{ Boys } & \multicolumn{2}{c|}{ Girls } & \multicolumn{2}{c|}{ Boys } & \multicolumn{2}{c|}{ Girls } \\
\hline & $\begin{array}{l}\text { Good } \\
\text { H.E. }\end{array}$ & $\begin{array}{l}\text { Poor } \\
\text { H.E. }\end{array}$ & $\begin{array}{l}\text { Good } \\
\text { H. E. }\end{array}$ & $\begin{array}{l}\text { Poor } \\
\text { H.E. }\end{array}$ & $\begin{array}{l}\text { Good } \\
\text { H. E. }\end{array}$ & $\begin{array}{l}\text { Poor } \\
\text { H.E. }\end{array}$ & $\begin{array}{l}\text { Good } \\
\text { H.E. }\end{array}$ & Poor H.E. \\
\hline Mean & 168.84 & 146.84 & 166.19 & 145.07 & 170 & 163.4 & 157.33 & 145.52 \\
\hline S.Ds & 9.13 & 7.9 & 8.58 & 11.1 & 9.58 & 10.03 & 4.6 & 7.99 \\
\hline
\end{tabular}

Table.2 Summary of ANOVA for the scores of mental health as a function of type of school, gender and home environment

\begin{tabular}{|c|c|c|c|c|}
\hline Source of variance & $\begin{array}{c}\text { Sum of } \\
\text { square }\end{array}$ & df & $\begin{array}{c}\text { Mean of } \\
\text { square }\end{array}$ & F - value \\
\hline A (type of school) & 319.416 & 1 & 319.416 & 4.058 \\
\hline B (gender) & 2632.016 & 1 & 2632.016 & $33.440^{* *}$ \\
\hline C (home-environment) & 7584.079 & 1 & 7584.079 & $96.356^{* *}$ \\
\hline A X B & 1610.144 & 1 & 1610.144 & $20.457^{* *}$ \\
\hline A X C & 765.144 & 1 & 765.144 & 9.722 \\
\hline B X C & 0.016 & 1 & 0.016 & 0.000 \\
\hline A X B X C & 9.072 & 1 & 9.072 & 0.115 \\
\hline Within group & 8815.426 & 112 & & \\
\hline
\end{tabular}


Fig.1 Mental health as a function of interaction of gender and type of school

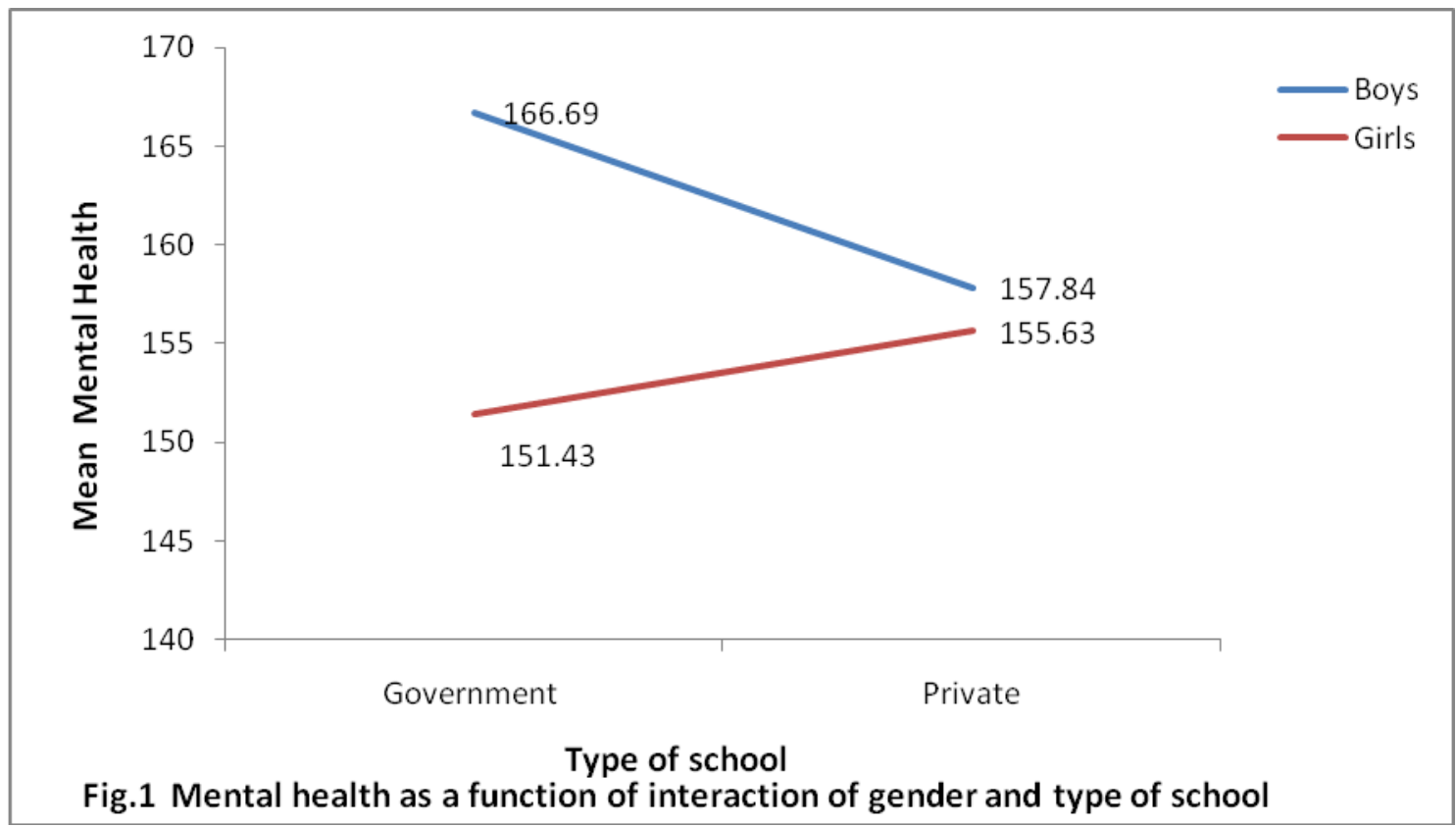

Furthermore, significant type of school $\mathrm{x}$ home environment interaction effect indicated that good homeenvironment group. Private school adolescents performed superior on group oriented attitude as compare government adolescents, however in case of poor home environment reverse in case of poor homeenvironment reverse pattern was found in government school adolescents (Fig. 1). It is apparent from this result that abusive experiences impaired the proper development of mental health.

Present finding have ample empirical supports (Puskar and Bernarelo, 2007). Rohner and Britreris (2002) longitudinal evidence reveals that parental rejection tends everywhere to precede the development of a variety of mental health problems, such as depression and depressed affect, conduct problems and behavior disorders and substance abuse. Rao and Tamta (2015) was found that high abused adolescents show poor mental health than low abused adolescents. Family factors play an important role in influencing the psychosocial adjustment particularly the positive mental health of Chinese adolescents (Shek, 1997).

Moreover, results revealed that difference between boys and girls on mental health was found significant. As finding indicate that girls were found inferior on mental health as compared to boys. Agarwal et al., (2010) found that male adolescents have better mental health then female adolescents. Type of school x gender Interaction effect was found significant Interaction graph show that in government group boys adolescents performed superior on mental health as compared to girls. Similarly a consistent pattern of increment was observed in case of private group adolescents. Present result have been supported by a number of studies (Chiang, 1995; Manju, 1995; Srivastva et al., 1987).

\section{References}

Agarwal, A. and Chowdhary, M. 2009. "The effect of Type A-Type B Behavior Pattern On Mental Health of Adolescents", Praachi J. Psycho-Cultural Dimensions, vol.25 (1and2).

Chiang, C.X. 1995. A study of stress Reaction among Adolescent. Chinese J. school Health, 26.

Goodwin, R.D. and Friedman, H.S. 2006. Health Status and the Five-factor Personality Traits in a Nationally Representative Sample. J. Health Psychol., 11(5); 643-654.

Jagdish and Srivastava, A.K. 1996. Manual of Mental Health Inventory, Varanasi Manovaigyanik Parikchan Sansthan.

Kendall and Tackett, K.A. 2001. Physiological correlates of childhood abuse: chronic hyper-arousal in PTSD, depression, and irritable bowel syndrome. Child Abuse Neglet, 24(6): 799-810.

Lanktree, C.B., Gilbert, A.M., and Briere, J. 2008. Multiinformant assessment of maltreated children: 
convergent and discriminate validity of the TSCC and TSCYC Child Abuse Neglect, 32: 621-25.

Lazenbatt, A. 2010. The impact of abuse and neglect on the health and mental health of children and young people.www.nspcc.org.uk/inform

Manjuvani, E. 1995. A study of the sex, Type of School, Standard and mental Health status of high school student. Experiments in Education, Vol XXIII. No.5, P 28-32.

Misra, K.S. 1989. Manual for Home- Environment Inventory, Agra: National Psychological Corporation.

Puskar, K.R. and Bernardo, L.M. 2007. Mental health and Academic Achievement Role of school Nurses. J. Specialists Pediatric Nursing, 12(4): 215-223.

Rao, M. and Tamta, P. 2015. Child Abuse: As a predictors of mental health in adolescents. Humanities and Social Science Studies, Vol. 4(1): 16.

Rohner, R.P., Britner, P.A. 2002. Worldwide mental health correlate of parental acceptance rejection:

How to cite this article:

Preeti Tamta, Pooja Arya. 2017. Impact of School and Family Background on Mental Health of Adolescents. Int.J.Curr.Res.Aca.Rev. 5(3), 20-24. doi: https://doi.org/10.20546/ijcrar.2017.503.003
Reviev of cross-cultural and intra-cultural evidence Cross- Cultural Res., 36: 16-47.

Shek, D.T. 1997. Family environment and adolescent psychological well-being school adjustment,and problem behaviour. A pioneer study in a Chinese context. J. Genetic Psychol., 158(4): 467-479.

WHO. 2001. Basic Documents. $43^{\text {rd }}$ Edition Geneva: World Health Organization.

Wentzel, K.R., and Caldwell, K. 1997. Friendship, peer acceptance and group membership: Relations to academic achievement in middle school. Child Development, 68(6): 1198-1209.

Yen, C.F., Hsu, C., Liu, S.C., Huang, C.F., Ko, C.H., Yen, J.Y. and Cheng, C.P. 2006. Relationships among mental health status, social context, and demographical characteristics in Taiwanese aboriginal adolescents: A structural equation model. Psychiatry and Clin. Neurosci., 60: 575-583. 